\title{
Analisis Strategi Pesan Content Marketing Untuk Mempertahankan Brand Engagement
}

\author{
Nigar Pandrianto, Gregorius Genep Sukendro \\ Fakultas Ilmu Komunikasi, Universitas Tarumanagara \\ Jl. Letjen S Parman No 1, Jakarta Barat 11440 \\ nigarp@fikom.untar.ac.id, geneps@fikom.untar.ac.id
}

\begin{abstract}
The use of social media as an alternative medium to communicate marketing messages is increasingly massive. In the landscape of the contemporary marketing industry that is commonly called content marketing. But the use of this medium is not always use the right strategy. The strategy in this context is content strategy. The result, this process does not show the expected results. One of them is that there is no significant brand awareness among audiences. Even though the use of marketing content appropriately can produce a very obvious engagament brand. Therefore it is always interesting to observe the content strategy used by a brand, then see if the strategy used is appropriate to the intended goal or not. Likewise with the marketing activities that Pasar Papringan tries to do through the Instagram account @ PasarPapringan. In this study the author will examine the marketing content of social media Instagram accounts Pasar Papringan. The research method used in this study is qualitative research. Meanwhile, the type of research used in this study is descriptive research that systematically describes facts or characteristics of certain populations in a factual and careful manner. From here the author will see whether the social media marketing content has been produced according to its purpose or not. The results of the study show that the content strategy chosen by the Pasar Papringan account is informative only, and this not relevant to the audience. The relevance of the content will be obtained if Pasar Papringan does a deeper profiling to the audience and explore themes that are relevant to the Pasar Papringan itself, like culinary, culture, dan peoples around Pasar Papringan.
\end{abstract}

Keywords: brand engagement, content marketing, social media

\begin{abstract}
Abstrak
Pemanfaatan media sosial sebagai medium alternatif untuk mengomunikasikan pesanpesan pemasaran semakin masif. Dalam lanskap industri marketing kontemporer ini yang lazim disebut konten marketing. Namun pemanfaatan medium ini tidak selalu dibarengi pemilihan strategi yang tepat. Strategi yang dimaksud adalah strategi konten. Akibatnya komunikasi yang dilakukan tidak memperlihatkan hasil yang memuaskan. Salah satunya adalah tidak terlihatnya brand engagament secara signifikan. Padahal pemanfaatan konten marketing secara tepat dapat menghasilkan brand engagament yang sangat kentara. Oleh sebab itu selalu menarik untuk mengamati strategi konten yang digunakan oleh sebuah brand, lalu melihat apakah startegi yang digunakan telah sesuai atau tepat denga tujuan yang diharapkan. Begitu juga dengan aktivitas marketing yang dicoba dilakukan oleh Pasar Papringan melalui akun Instagram @PasarPapringan. Dalam penelitian ini penulis akan meneliti konten marketing media sosial akun Instagram Pasar Papringan. Metode penelitian yang digunakan dalam penelitian ini adalah penelitian kualitatif. Sedangkan, jenis penelitian yang digunakan dalam penelitian ini adalah
\end{abstract}


penelitian yang sifatnya deskriptif yang menggambarkan secara sistematis fakta atau karakteristik populasi tertentu secara faktual dan cermat. Dari sini penulis akan melihat apakah konten marketing media sosial tersebut telah diproduksi sesuai tujuannya atau belum. Hasil penelitian memperlihatkan strategi konten yang dipilih oleh akun Pasar Papringan masih bersifat informatif, dan belum relevan dengan audiens. Relevansi konten akan diperoleh jika Pasar Papringan dapat melihat lebih dalam profil audiens dan mengeksplorasi tema-tema yang relevan dengan Pasar Papringan itu sendiri, seperti kuliner, kebudayaan, orang-orang yang ada di seputar Pasar Papringan.

Kata Kunci: brand engagement, konten marketing, media sosial

\section{Pendahuluan}

Penggunaan media digital sebagai salah satu medium komunikasi semakin mendapat tempat dalam berbagai industri. Hal ini dipicu oleh meluasnya penggunaan perangkat komunikasi berbasis digital yang juga kian masif, dan kian terjangkaunya biaya akses data internet. Salah satu indikasinya adalah hasil survey yang dilakukan oleh majalah Marketeers (2017). Dari hasil survey tersebut terlihat tren pemanfaatan media digital sebagai sumber informasi oleh anak muda cukup tinggi, terutama di kota-kota besar. Di Jabodetabek misalnya, penggunaan internet sebagai sumber informasi tercatat sangat tinggi, yakni mencapai 60\% (n: 900) ketimbang sumber dari televisi maupun surat kabar. Angka yang sama juga didapati di Surabaya (n: 780). Di Semarang, catatan yang sama mencapai 53\% (n: 596), diikuti berturut-turut di kota-kota Manado (52\%, n: 584), dan Bandung (49\%, n: 775). Meskipun di beberapa kota terlihat persentase penggunaan televisi sebagai sumber informasi berada di atas internet, tetapi persentase penggunaan internet rata-rata berada di atas penggunaan surat kabar sebagai sumber akses informasi. Hal di atas memperlihatkan komunikasi yang dilakukan melalui medium digital kini juga memiliki peluang yang besar untuk menarik perhatian target konsumen selain media-media konvensional.

Fakta ini ternyata telah mendorong banyak perusahaan maupun lembaga ikut memanfaatkan media digital sebagai sarana berkomunikasi dengan konsumen. Mereka bergegas melakukan ini agar selalu dapat memelihara engagement dengan konsumen yang terus berubah dari waktu ke waktu. Mereka yakin tanpa langkah-langkah ini sulit untuk dapat terus menjaga relasi yang baik dengan calon konsumen. Dengan langkah-langkah ini mereka berharap untuk terhindar dari dampak disruptif. Mereka tidak mau menjadi pemain lama yang tiba-tiba harus bergeser karena kehadiran media baru yang ternyata mensyaratkan perubahan yang mendasar. Sekuat apapun brand loyalty yang telah dibangun oleh incumbent melalui strategi komunikasi pemasaran konvensional, posisi incumbent tetap akan terancam pada era yang serba disruptif ini (Kasali, 2017)

Di tengah riuhnya penggunaan platform digital sebagai medium komunikasi, hal yang paling harus diperhatikan dalam platform ini adalah formulasi konten atau pesan yang akan dikomunikasikan kepada audiens. Pesan atau konten merupakan unsur komunikasi yang sangat penting (Cangara, 2017) termasuk dalam komunikasi pemasaran. Konten ini kemudian lazim disebut content marketing. 
Nigar Pandrianto, Gregorius Genep Sukendro : Analisis Strategi Pesan Content Marketing Untuk Mempertahankan Brand Engagement

Prinsip content marketing adalah menawarkan konten, di media cetak maupun media digital, yang relevan dengan target market. Konsekuensinya, konten harus didesain secara khusus sesuai kebutuhan target market. Situasi ini kemudian memunculkan fenomena "media rent to media own". Menurut J Rowley (dalam Yazdanifard dan Kee, 2015), content marketing adalah manajemen yang memastikan identifikasi secara secara pasti, dengan analisa yang kuat untuk menarik perhatian calon customer yang didistribusikan lewat media digital.

Content marketing biasanya disusun sesuai kebutuhan target market secara spesifik dan diproduksi dengan teknik story telling sehingga lebih mudah diterima oleh target market. Konsekuensinya, pesan harus dirancang sedemikian agar dapat menghasilkan efek yang diharapkan. Apalagi konten media digital semakin overloaded sehingga hanya konten yang benar-benar menarik perhatian, dan dikemas dengan baik, yang akan mendapat perhatian audience (Gamble, 2016).

Tak hanya itu, content marketing yang dibangun pun harus memiliki sejumlah syarat, seperti berguna (usability) dan mudah diakses (accessibility). Usability artinya konten media digital memiliki desain yang sederhana, elegan, serta memiliki fungsi yang jelas. Tujuannya konten dapat mendorong audiens untuk melakukan apa yang diinginkan oleh pemilik konten secara efektif. Sedangkan accessibility adalah konten dapat diakses oleh setiap orang secara equal, artinya tidak ada batasan atas siapa saja yang dapat dapat mengakses konten, termasuk bagi audiens yang difabel. Itu artinya pengelola harus menyediakan konten dengan format beragam sehingga pesan dapat dikonsumsi secara visual, tekstual secara interaktif (Ryan, 2017).

Ketika berbicara mengenai media digital, seorang marketer tidak bisa lepas dari content marketing. Content marketing memungkinkan marketer melakukan kontak dengan potential customer (Ryan, 2017). Oleh sebab itu content dalam perspektif media digital harus mendapat perhatian serius dari seorang marketer sebesar apapun brand yang dimiliki. Strategi inipun sudah dilakukan oleh sejumlah brand besar kelas dunia, sebut saja $P \& G$, Coca-Cola, hingga American Express. Bahkan, mereka telah mencanangkan Content 2020 yang dideskripsikan sebagai $24 / 7$ connectivity yang menyebutkan bahwa marketer harus masuk ke ranah content untuk menciptakan komunikasi yang lebih segar (fresh), relevan, dan kontekstual (Ryan, 2017).

Content marketing dianggap dapat menciptakan kedekatan dengan audiens sehingga marketer lebih mudah mencapai tujuan kegiatan komunikasi pemasaran. Namun, syarat yang harus dipenuhi adalah relevansi konten dengan audiens (Gamble, 2016). Content marketing dapat didistribusikan (dipublikasikan) lewat beberapa medium, misalnya saja website, media sosial, blog, vlog, dan aplikasi pada tablet maupun smartphone. Pemilihan media ini disesuaikan dengan target market yang dituju serta karakteristik isi maupun tujuan pesan.

Begitu juga dengan Pasar Papringan yang terbilang unik. Keunikan pasar yang berlokasi di Desa Ngadiprono, Kabupaten Temanggung, Jawa Tengah ini adalah posisinya yang berada di area kumpulan pohon bambu. Untuk mengomunikasikan kegiatan yang dilakukan oleh Pasar Papringan, pihak Pasar Papringan telah membuat sebuah akun di media sosial. 
Salah satu media sosial yang digunakan oleh Pasar Papringan adalah Instragram. Nama akun yang digunakan untuk keperluan komunikasi ini adalah @ pasarpapringan. Akun ini dianggap efektif karena proses komunikasi dengan audiens dapat berjalan dengan baik. Apalagi jumlah pengunjung Pasar Papringan selalu meningkat dari waktu ke waktu. Namun, ini memang tidak dapat menunjukkan bahwa engagement antara Pasar Papringan dan audiens tercapai sesuai harapan. Alasannya, jumlah like, comment, conversation, hingga share masih tergolong rendah.

Apa yang dilakukan oleh Pasar Papringan memang tak keliru, sebab kini media yang banyak digunakan oleh masyarakat sekarang ini untuk berkomunikasi. Media sosial memiliki fungsi untuk dapat mendukung interaksi sosial bagi para penggunanya. Media sosial dapat digunakan untuk berinteraksi dengan teman, berbagi informasi, juga mendapatkan teman-teman baru yang sama-sama menggunakan akun media sosial tersebut. Mayfield mendefinisikan media sosial sebagai pemahaman terbaik dari kelompok jenis baru media online yang mencakup karakter-karakter partisipasi, keterbukaan, percakapan, komunitas, dan konektivitas (dalam Leksono, 2011).

Kehadiran media sosial ini membuat keputusan pembelian memiliki faktor yang lebih kompleks. Hal ini disebabkan oleh interaksi melalui media sosial seperti brand conversation, brand mention memberikan pengaruh yang tidak kecil dalam keputusan pembelian. Begitu juga dengan social metric lainnya seperti jumlah follower, jumlah like, sampai jumlah share (Ryan, 2015).

Kelebihan media sosial ini, seperti diungkapan oleh Schiffman dan Kanuk (dalam Marta, 2016) adalah addressable, yakni pesan dapat disampaikan secara khusus meskipun penerima pesan yang lain dapat menerima esensi pesan yang sama, dan interactive, dalam arti penerima pesan dapat berinterkasi secara khusus dengan pengirim pesan, dan bahkan ia bisa dengan mudah menyebarkannya.

Selain itu, dari hasil pengamatan, penelitian mengenai content marketing hingga kini lebih banyak bergulir di wilayah pengukuran seperti impact (Ahmad, 2016), kepuasan pelanggan, dan wilayah bisnis content marketing (Kee, 2015) itu sendiri. Namun, penelitian yang memberikan penekanan pada strategi pesan belum ditemukan. Padahal penentuan ataupun perumusan strategi pesan memiliki peran penting dalam keberhasilan content marketing.

Menurut Cangara, secara umum pesan adalah segala sesuatu yang disampaikan oleh seseorang dalam bentuk simbol dan dipersepsi dan diterima oleh khalayak dalam serangkaian makna (Cangara, 2017). Selanjutnya, masih menurut Cangara, simbol-simbol tersebut dapat berupa verbal dan non-verbal. Namun, pesan ini harus disusun dan didesain sedemikian rupa sehingga sesuai dan dapat diterima oleh audiens secara mudah. Ini sejalan dengan sifat-sifat sebuah pesan yakni pesan bersifat informatif dan pesan bersifat persuasif (Cangara, 2017). Pesan yang bersifat informatif lazimnya terkait informasi sehari-hari seperti pada berita, penerangan ataupun pengetahuan, dan pesan bersifat memberikan edukasi.

Khusus pesan bersifat persuasif, pesan ini diproduksi untuk tujuan tertentu. Dalam komunikasi pemasaran misalnya, pesan persuasif banyak diproduksi untuk mengajak audiens untuk mengenal dan membeli atau 
Nigar Pandrianto, Gregorius Genep Sukendro : Analisis Strategi Pesan Content Marketing Untuk Mempertahankan Brand Engagement

mengonsumsi produk tertentu. Sedangkan dalam perspektif politik, pada pemilihan umum misalnya, pesan persuasif diproduksi untuk mendorong audiens untuk memilih calon tertentu.

Dalam konteks pesan persuasif ada beberapa cara penyusunan yang dapat digunakan agar pesan tersebut dapat mencapai tujuan komunikasi (Cangara, 2017) yakni: (1) Pesan yang menakutkan (fear appeal), pesan yang disusun untuk menimbulkan ketakutan kepada khalayak. (2) Pesan yang penuh emosi (emotional appeal), pesan yang berusaha menggugah emosi audiens. (3) Pesan yang penuh janji (reward appeal), pesan yang penuh dengan janji. (4) Pesan yang penuh dengan dorongan (motivational appeal), pesan yang disusun untuk menumbuhkan emosi pada khalayak. (5) Pesan yang penuh humor (humorous appeal), pesan yang diproduksi untuk membuat khalayak tidak jenuh, lebih cair, dan lebih segar.

Penelitian ini bertujuan untuk melihat bagaimana strategi pesan content marketing Pasar Papringan di media digital untuk memelihara engagement target market.

\section{Metode Penelitian}

Metode penelitian yang digunakan dalam penelitian ini adalah penelitian yang bersifat kualitatif. Istilah kualitatif sendiri mempunyai makna yang beragam menurut ahli. Creswell yang dikutip Raco (2010) mendefinisikan penelitian kualitatif sebagai suatu pendekatan atau penelusuran untuk mengeksplorasi dan memahami suatu gejala sentral. Untuk mengerti gejala sentral tersebut, peneliti sebagai partisipan mewawancarai narasumber dengan mengajukan pertanyaan yang umum dan lebih luas.

Sedangkan, jenis penelitian yang digunakan dalam penelitian ini adalah penelitian yang sifatnya deskriptif. Metode deskriptif menggambarkan secara sistematis fakta atau karakteristik populasi tertentu secara faktual dan cermat. Jadi, metode penelitian deskriptif adalah mengumpulkan informasi yang aktual secara rinci serta melihat gejala-gejala yang ada di dalam penelitian dan mengidentifikasi masalah tersebut data dari hasil penelitian ini disusun secara kualitatif. Tujuan metode penelitian ini lebih kepada membuat gambaran secara sistematis, faktual, dan akurat tentang fakta-fakta dan sifat-sifat objek tertentu.

Dalam penelitian ini, metode pengumpulan data adalah teknik atau caracara yang dapat digunakan dalam riset untuk mengumpulkan informasi yang diperlukan untuk memperoleh kebenaran. Teknik pengumpulan data yang digunakan dalam penelitian ini melalui beberapa cara, yaitu: observasi dan wawancara.

Patton, dalam Raco (2010) menjelaskan bahwa observasi adalah pengamatan oleh peneliti. Data ini dapat memberikan gambaran yang ada di lapangan. Gambaran ini bisa berupa sikap, tindakan, pembicaraan, interaksi interpersonal atau yang lainnya. Dari observasi ini diperoleh banyak hal dari lapangan, yang mungkin tidak bakal terungkap dari wawancara.

Masih dikutip oleh Raco (2010) wawancaca dapat digunakan sebagai salah satu bentuk pengumpulan data. Namun wawancara ini harus dilakukan secara mendalam (in-depth). Pertanyaan yang digunakan harus bersifat open-ended. Data 
yang diperoleh dapat saja berupa persepsi, pendapat, perasaan, dan pengetahuan. Pada penelitian ini wawancara dilakukan dengan menggunakan pedoman wawancara. Sumber data yang diperlukan tersebut dicatat melalui catatan tertulis dan juga dapat melalui perekaman audio. Sedangkan narasumber wawancara ini adalah praktisi strategi konten marketing, dan pengelola akun Instagram Pasar Papringan.

\section{Hasil Penemuan dan Diskusi}

Keberadaan Pasar Papringan adalah muara dari gagasan Singgih S. Kartono. Pendiri Magno Design dan Spedagi yang berbasis di Temanggung, Jawa Tengah. Pasar Papringan, yang berlokasi di Desa Ngadiprono, Temanggung, digagas karena Singgih melihat potensi yang ada di desa ini. Potensi tersebut adalah bambu yang dihasilkan oleh desa ini. Singgih melihat bambu dari desa ini dapat dimonetisasi jika dikelola secara serius. Namun pada perkembangannya tidak hanya bambu yang dapat dikelola dari desa ini. Singgih Karsono, penggagas sekaligus pendesain konsep Pasar Papringan, melihat kawasan hutan bambu dapat dikelola menjadi sebuah pasar tradisional yang dapat menarik perhatian pengunjung.

Untuk meningkatkan awareness masyarakat terhadap keberadaan Pasar Papringan, dilakukanlah strategi komunikasi media digital. Salah satu perangkat yang digunakan adalah media sosial, dalam hal ini media sosial yang digunakan adalah Instagram. Ini dilakukan karena penggunaan media sosial ini dianggap semakin masif.

Sebagai contoh, merujuk data yang dimiliki oleh WeAreSocial.Net, seperti dikutip oleh Teknologi.id, pada Januari 2018, Indonesia merupakan salah satu negara yang dengan pemilik akun aktif Instagram terbanyak di dunia, yakni sekitar 55 juta pengguna. Jumlah ini meletakkan Indonesia pada peringkat ketiga setelah Amerika Serikat dan Brasil. Jumlah ini dipastikan akan bertambah, karena pada bulan Juni 2018, pengguna Instagram telah mencapai 1 miliar. Artinya ada tambahan sekitar 200 juta pengguna aktif selama enam bulan terakhir (Kompas.com).

Akun Pasar Papringan di Instagram hadir sejak 2016. Hingga Oktober 2018, akun Pasar Papringan di telah memiliki lebih dari 23.000 pengikut (follower) di Instagram. Jumlah ini diraih dalam waktu hampir tiga tahun. Konten pertamanya didistribusikan pada Januari 2016.

Dari pengamatan yang dilakukan pada distribusi konten Pasar Papringan, terdapat beberapa hal penting yang dapat dicatat. Catatan tersebut antara lain ialah distribusi konten yang bersifat informatif, artinya hanya bersifat memberitahukan informasi yang mengenai kegiatan yang akan dilakukan oleh Pasar Papringan. Konten ini hanya berisi tanggal, waktu, dan hari penyelenggaraan Pasar Papringan.

Konten-konten sejenis ini didistribusikan dua minggu, satu minggu, dan beberapa hari sebelum kegiatan Pasar Papringan dilaksanakan. Tujuannya adalah untuk memberitahukan pelaksanaan kegiatan dalam hitungan mundur. Dengan kata lain informasi ini merupakan teaser yang mendorong rasa ingin tahu audiens 
Nigar Pandrianto, Gregorius Genep Sukendro : Analisis Strategi Pesan Content Marketing Untuk Mempertahankan Brand Engagement

untuk mengetahui lebih jauh informasi berikutnya, sebagai pesan yang penuh dengan dorongan (motivational appeal) (Cangara, 2017) terwujudnya Brand Engagement.

Selain itu, hasil pengumpulan data memperlihatkan bahwa, akun Pasar Papringan juga mendistribusikan konten-konten yang berisi jadwal kegiatan Pasar Papringan. Konten-konten ini disampaikan satu hingga tiga bulan sebelum acara dilakukan. Jadwal ini disampaikan agar audiens memahami bahwa kegiatan Pasar Papringan hanya dilakukan pada pada hari-hari tertentu (hari Minggu Pon dan Wage menurut kalender atau penanggalan Jawa).

Konten ini diberikan untuk menegaskan kembali bahwa Pasar Papringan tidak diadakan setiap minggu. Pasalnya, menurut Singgih, penggagas Pasar Papringan, banyak orang, terutama dari luar kota, mengira pasar ini diadakan setiap minggu, padahal aktivitas ini dilakukan rata-rata dua kali dalam sebulan, yakni pada hari Minggu Wage dan Pon (menurut penanggalan Jawa). Sehingga, jadwal Pasar Papringan adalah konten yang dianggap perlu untuk selalu disampaikan.

Selain konten-konten tersebut, konten lain yang sering didistribusikan oleh akun Pasar Papringan adalah aktivitas pengunjung serta para pedagang yang berada di pasar Pasar Papringan. Konten ini dimasukkan ke dalam salah satu kategori konten yang harus didistribusikan karena dari situ akan terlihat apa saja yang yang terjadi di pasar tersebut selama acara berlangsung

Konten-konten ini didistribusikan agar para follower dapat melihat suasana ketika aktivitas berlangsung. Suasana yang memperlihatkan keceriaan pengunjung, kehangatan suasana, dan keantusiasan pengunjung selama berada di pasar yang berlangsung sekitar enam jam itu.

Selain itu, dari konten yang didistribusikan terlihat Pasar Papringan ingin menunjukkan sejumlah hal yang tidak biasa atau hal yang sudah jarang ditemui di kehidupan sehari-hari. Hal-hal tersebut misalnya dijualnya beberapa jenis kuliner (baik masakan dan panganan ringan) yang sudah jarang dijajakan di pasar-pasar modern. Bagi sebagian orang, konten-konten ini (hal yang tidak biasa) mengundang rasa ingin tahu. Ditunjang oleh foto-foto menarik, konten-konten ini semakin mudah dicerna para follower maupun audiens lainnya.

Namun, dari konten-konten yang telah didistribusikan tersebut terlihat keragaman yang sangat kurang, padahal banyak kategori konten lain yang dapat dimasukkan ke dalamnya yang tidak kalah menarik, tetap relevan, dan mendorong level of engagement.

Hal ini diakui oleh Ade Putri Paramadita, seorang content strategist media sosial. Menurutnya, kekurangan konten-konten Instagram Pasar Papringan adalah variasi konten. Menurutnya, banyak variasi konten yang dapat didistribusikan. Misalnya saja soal kuliner. Konten mengenai kuliner akan menarik karena di Pasar Papringan banyak jenis kuliner yang semakin jarang ditemui orang ditawarkan kepada pengunjung. Kuliner-kuliner ini akan menjadi sesuatu yang menarik jika diperkenalkan kepada para follower akun Instagram Pasar Papringan.

Makanan Gablog Pecel misalnya, adalah makanan yang sangat jarang ditemukan. Karena, makanan ini hanya muncul pada acara-acara besar saja. Menjadi sesuatu yang menarik ketika makanan ini hadir di Pasar Papringan. 
Tidak mengherankan jika banyak pengunjung yang mencicipi makanan ini karena ingin merasakan makanan yang mungkin jarang ditemui. Selain itu, makanan tradisional lain yang juga semakin sulit ditemukan, juga bisa didapat di Pasar Papringan.

Sebenarnya tidak sekadar deskripsi makanan, Pasar Papringan juga dapat menjelaskan mulai dari nama makanan, bahan-bahannya, cara mengolahnya, cara memakannya, asal makanan, dan khasiat aneka makanan itu. Informasi-informasi ini akan sangat bermanfaat tidak hanya bagi mereka yang berniat mengunjungi Pasar Papringan, tetapi juga bagi mereka yang belum pernah mengunjungi Pasar Papringan.

Hal ini tentu saja tidak hanya berlaku bagi menu makanan, tetapi juga menu minuman. Jika memasuki Pasar Papringan pengunjung dapat melihat ada beberapa jenis minuman yang dijajakan, seperti kopi, wedang jahe, dan wedang ilalang. Dari informasi yang disampaikan oleh para penjual minuman ini, wedang jahe dipercaya dapat membuat selalu fit jika dikonsumsi secara rutin. Begitu juga dengan wedang ilalang. Ini dapat menjadi konten yang menarik jika dimasukkan ke dalam salah satu konten yang didistribusikan melalui akun Pasar Papringan.

Ade juga menyarankan, sebenarnya bukan hanya makanan yang dijajakan di Pasar Papringan saja yang ditulis, tetapi juga aneka makanan yang berasal dari Jawa Tengah. Alasannya Pasar Papringan berada di Jawa Tengah, jadi kontenkonten terkait kuliner yang berasal dari Jawa Tengah juga relevan untuk dimasukkan.

Selain itu, potensi wisata lain yang ada di Jawa Tengah, khususnya Temanggung, dapat juga dimasukkan. Ini menarik karena mereka yang datang di Pasar Papringan mungkin ingin juga melihat atau mendatangi obyek wisata lain yang juga menarik dan menantang untuk dicoba. Bahkan tidak jauh dari lokasi Pasar Papringan terdapat aliran sungai menjadi incaran para penggemar body tube atau meluncur di sungai dengan menggunakan pelampung yang berasal dari ban dalam mobil. Belum lagi Temanggung sebagai daerah penghasil tembakau. Tentu saja banyak cerita yang dapat dieksplorasi dan menjadi konten yang tidak kalah menarik.

Desa tempat Pasar Papringan digelar pun memiliki banyak hal yang dapat dijadikan konten. Sebagai contoh, desa dimana Pasar Papringan berada adalah pengahsil bambu. Di desa ini nambu yang dapat dijadikan berbagai barang keperluan rumah tangga sehari-hari. Fakta ini sebenarnya dapat dijadikan konten yang cukup atraktif untuk disampaikan kepada audiens. Apalagi semangat awal Pasar Papringan adalah untuk memberdayakan masyarakat. Berarti konten-konten akun Pasar Papringan juga harus dapat menampilkan apa yang dapat diberdayakan di masyarakat.

Intinya, Pasar Papringan masih bisa mengidentifikasi dan menginventarisasi lebih banyak material konten. Mereka harus jeli dan detail melihat lingkungan sekitar agar lebih banyak konten relevan yang dapat didistribusikan. Sayangnya hal itu belum dilakukan secara maksimal oleh Pasar Papringan. 
Nigar Pandrianto, Gregorius Genep Sukendro : Analisis Strategi Pesan Content Marketing Untuk Mempertahankan Brand Engagement

\section{Simpulan}

Dari pembahasan di atas penulis menyimpulkan bahwa Pasar Papringan belum maksimal dalam menyiapkan strategi dan formula dalam menyiapkan konten marketing media sosial sebagai pesan penuh untuk dorongan (motivational appeal) terwujudnya Brand Engagement. Dalam hal ini mereka harus dapat mendefinisikan atau merumuskan kembali apa tujuan-tujuan utama dalam pendistribusian konten digital melalui media sosial.

Selain itu Pasar Papringan juga harus melakukan kategorisasi konten yang akan didistribusikan pada akun miliknya. Kategorisasi harus dilakukan sesuai tujuan-tujuan yang diharapkan. Selain itu, kategorisasi ini harus memperlihatkan sebuah kesatuan yang kemudian dapat dibaca sebagai sebuah pesan utama.

Pasar Papringan juga harus melakukan perubahan terhadap desain konten marketing-nya, dengan melihat kembali bagaimana pesan dikelola, diprioritaskan, dan dipresentasikan. Pengelola akun juga harus kembali menentukan kemana konten harus diarahkan atau difokuskan. Hal ini tentu saja mensyaratkan tujuan pasti atas diproduksinya konten marketing media sosial. Dari situ, dapat ditentukan ragam konten marketing yang benar-benar membawa dampak atau manfaat bagi meningkatnya tingkat engagement Pasar Papringan.

\section{Ucapan Terima Kasih}

Publikasi penelitian ini tidak dapat diwujudkan karena bantuan dari beberapa pihak. Untuk itu rasa terima kasih layak dialamatkan kepada Direktorat Penelitian dan Pengabdian Kepada Masyarakat Universitas Tarumanagara yang telah memungkinkan penelitian ini terlaksana. Kemudian pihak Fakultas Ilmu Komunikasi Universitas Tarumaagara yang telah memberikan waktu kepada penulis untuk melakukan penelitian. Tidak lupa ucapan terima kasih perlu disampaikan kepada pihak Pasar Papringan dan narasumber Ade Putri Paramadita yang telah meluangkan waktu untuk berdiskusi dengan penulis mengenai konten digital.

\section{Daftar Pustaka}

Ahmad, N. S., Musa, R., Harris, M., \& Harun, M. (2016). The 1mpact of Social Media Content Marketing (SMCM) towards brand health. Procedia Economics and Finance, Volume 37, Halaman 331-336

Bohang, Fatimah Kartini. (2018). Juni 2018, Pengguna Aktif Instagram Tembus 1 Miliar. Desember 20, 2018. Kompas Online. https://tekno.kompas.com/read/2018/06/21/10280037/juni-2018pengguna-aktif-instagram-tembus-1-miliar.

Cangara, Hafied. (2017). Perencanaan dan Strategi Komunikasi. Jakarta : Rajawali Press.

Gamble, Stephen. (2016). Visual Content Marketing Leveraging Infographics, Video, and Interactive Media to Attract and Engage Customers. Canada: Willey. 
Kasali, Rhenald. (2017). Disruption. Jakarta: Gramedia Pustaka Utama.

Kertajaya. (2017). Marketing Changes in Challenging Times. Jakarta : Gramedia Pustaka Utama dan Markplus. Inc.

Lim, Hendrik. (2016). New Games, New response, Strategy to Win The Market Changes. Jakarta : Defora Publisher.

Marta, Rustono Farady., \& William, Denise Monica. (2016). Studi Terpaan Media Pemasaran Melalui Posting Instagram Terhadap Ekuitas Merek Pelanggan Sumoboo! (Analisis Eksplanatif pada Komunitas Food Blogger \#WTFoodies). Jurnal Komunikasi, Volume 8, No: 1, Halaman 68-82. https://journal.untar.ac.id/index.php/komunikasi/article/view/50/53

Prisgunanto, Ilham. (2006). Komunikasi Pemasaran: Strategik dan Taktik. Bogor: Penerbit Ghalia Indonesia.

Raco, ME., M.Sc. (2010). Metode Penelitian Kualitatif, Jenis, Karakter dan Keunggulannya. Jakarta: Grasindo.

Ryan, Damian. (2015). Understanding Social Media, How to Create a Palan for Your Business That Works. London: Kogan Page.

Ryan, Damian. (2017). Understanding Digital Media, Marketing Strategies for Engaging The Digital Generation. London : Kogan Page.

Saeed, Rashid. (2015). Brand Activation, A Theoretical Perspective. Journal of Marketing and Consumer Research

Yazdanfirad., \& Kee. (2015). The Review of Content Marketing as a New Trend in Marketing Practices. International Journal of Management, Acounting and Economics, Vol. 2 No.9.

Yulianita, Neni., \& Leksono, Ninok. (2011). Corporate and Marketing Communication. Bandung : Asosiasi Pendidikan Ilmu Komunikasi. 